Article

\title{
Mesoporous Silicas with Tunable Morphology for the Immobilization of Laccase
}

\author{
Victoria Gascón, Isabel Díaz, Carlos Márquez-Álvarez and Rosa M. Blanco * \\ Instituto de Catálisis y Petroleoquímica, CSIC, Marie Curie 2, Madrid 28049, Spain \\ * Author to whom correspondence should be addressed; E-Mail: rmblanco@icp.csic.es; \\ Tel.: +34-915-854-636; Fax: +34-915-854-760.
}

Received: 8 May 2014; in revised form: 20 May 2014 / Accepted: 23 May 2014 /

Published: 30 May 2014

\begin{abstract}
Siliceous ordered mesoporous materials (OMM) are gaining interest as supports for enzyme immobilization due to their uniform pore size, large surface area, tunable pore network and the introduction of organic components to mesoporous structure. We used SBA-15 type silica materials, which exhibit a regular 2D hexagonal packing of cylindrical mesopores of uniform size, for non-covalent immobilization of laccase. Synthesis conditions were adjusted in order to obtain supports with different particle shape, where those with shorter channels had higher loading capacity. Despite the similar isoelectric points of silica and laccase and the close match between the size of laccase and the pore dimensions of these SBA-15 materials, immobilization was achieved with very low leaching. Surface modification of macro-/mesoporous amorphous silica by grafting of amine moieties was proved to significantly increase the isoelectric point of this support and improve the immobilization yield.
\end{abstract}

Keywords: amorphous silica; biocatalysts; enzyme immobilization; functionalization; grafting; laccase; MS-3030; ordered mesoporous materials; SBA-15; support

\section{Introduction}

Siliceous ordered mesoporous materials (OMMs) are gaining interest as supports for enzyme immobilization because of their uniform and tunable pore size and large surface area, which make them excellent hosts for the adsorption of bulky molecules like enzymes [1-5]. OMMs are thermally, mechanically and chemically stable and insoluble in the solution used for the immobilization process 
and their surface can be grafted with different functionalities [6-10]. The immobilization of enzymes in functionalized OMMs can increase the operational stability, durability and importantly, the catalyst particles can be easily separated and reused without loss of catalytic activity $[11,12]$.

To evaluate the suitability of a mesoporous material for enzyme immobilization the following factors are to be considered: pore diameter, surface area, pore volume, particle size, morphology, as well as surface modification. The effects of pore size and enzyme-support material interactions have demonstrated to have significant roles in the enzyme loading and activity. Surface chemical modification of the support could further enhance interactions between the pore walls and the enzyme [12]. In addition, the diffusion phenomena related to particle size are greatly affected by the support morphology $[4,13]$.

Enzymes can be immobilized in mesoporous materials by different methods: adsorption, covalent attachment or encapsulation [4]. Covalent attachment is not advisable when pore size is close to enzyme dimension because of a "stopper" effect which may result in low immobilization yield, and always requires chemical modification of the enzyme which may result in catalytic activity decay. Adsorption seems more suitable because both drawbacks are avoided. However the driving forces of non-covalent immobilization are relatively weak interactions and, therefore, a careful design of the mesoporous support is necessary.

Laccases (E.C. 1.10.3.2) are a group of multicopper enzymes of industrial interest that catalyze the oxidation of phenolic compounds such as ortho- and para-diphenols to their corresponding quinones with the concomitant reduction of oxygen to water [14-18]. Their potential as biocatalysts for use in several biotechnological processes, in nanobiotechnology applications, in food processing and in green chemistry [19-26] is limited by their low operational stability, mostly due to their rapid inactivation by different factors [12].

In this article we deal with the synthesis of SBA-15 type mesoporous silica supports with different particle morphology offering improved diffusional properties. SBA-15 with conventional rod type of particles, showing long channels (SBA-15-L) is compared with hexagonal particles formed by short mesochannels (SBA-15-S). Finally, we evaluate the incorporation of amine groups in large pore-size amorphous silica via grafting method (MS-3030-N). The morphology of SBA-15 structure, the effect of aminopropyl surface groups on the laccase immobilization behavior and detailed characterization results will be discussed in order to shed some light on the immobilization of enzymes. The laccase immobilization yields on pure silicas and the functionalized amorphous silica, specific activity measurements as well as enzyme leaching tests of immobilized laccase are also reported.

\section{Results and Discussion}

\subsection{Characterization of Supports}

The SBA-15 materials were characterized by X-ray diffraction, scanning and transmission electron microscopy to evaluate the morphology and internal structure of the particles, and nitrogen adsorption, to obtain the textural properties of the supports.

X-ray diffraction patterns of the SBA-15 materials synthesized with different surfactants, conditions and silica sources corroborated the 2D p6mm mesostructure with a unit cell parameter $a_{o}$ of $11.1 \mathrm{~nm}$ 
(data not shown). The desired effect of morphology modification was observed by scanning electron microscopy. SEM images of SBA-15-L and SBA-15-S are shown in Figure 1. The structure of SBA-15-L particles is fiber-like or elongated rod, formed by aggregates of rods connected into ropelike macrostructures (Figure 1A). The average particle size is $0.75-1 \mu \mathrm{m}$ in length and about $2 \mu \mathrm{m}$ in width (Figure 1B,C). SBA-15-S particles exhibit hexagonal dish-shaped morphology or short rod (Figure 1D-F). The average particle size is $5 \mu \mathrm{m}$ in diameter and $0.2 \mu \mathrm{m}$ width. Moreover, the alignment of channels with the axial direction of the rod-like particles on SBA-15-L and SBA-15-S could be corroborated by transmission electron microscopy (TEM).

Figure 1. SEM micrographs of mesoporous silicas: SBA-15-L (A-C), SBA-15-S (D-F).
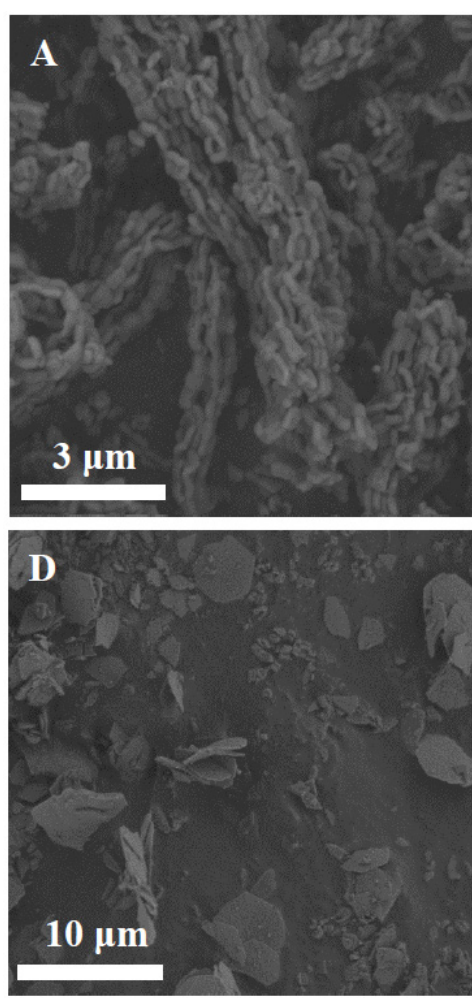
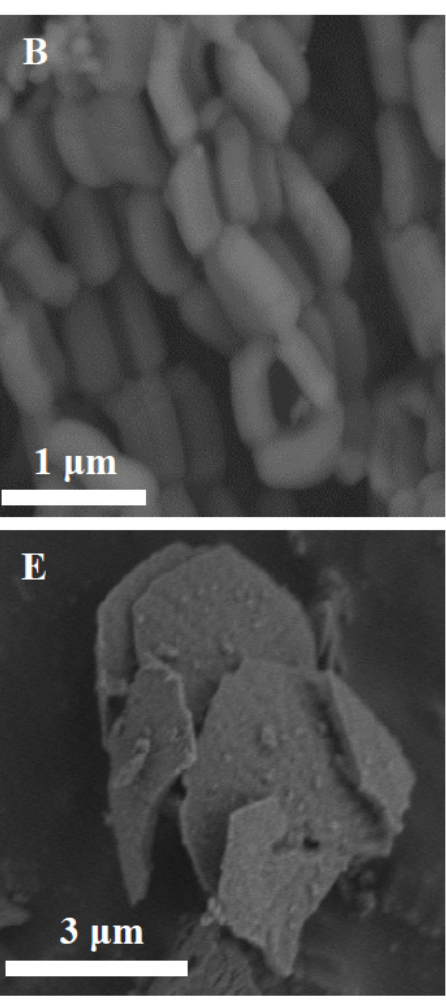

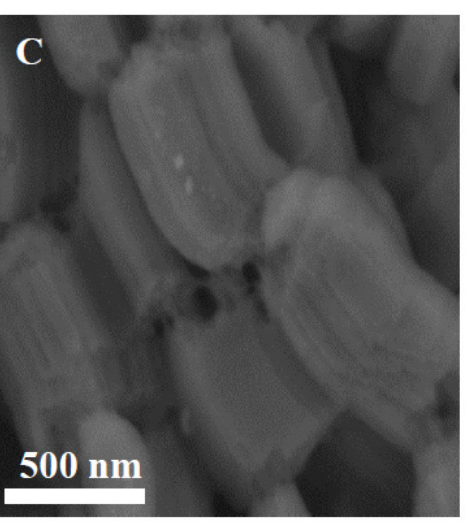

F

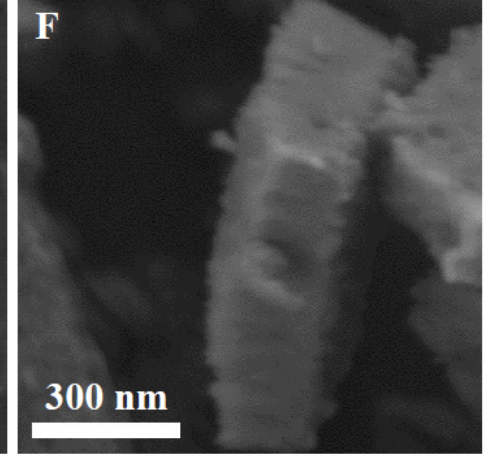

Figure 2 displays representative TEM images of these materials showing the projection in the direction perpendicular to the channels in the longitudinal axis of sample SBA-15-L (Figure 2A). The hexagonal symmetry of the pores, like a honeycomb, characteristic of this kind of symmetry is also observed when the image is taken in the direction parallel to the mesochannels and along the short axis of the dish in sample SBA-15-S (Figure 2B). In both cases, the images allow observing the respective morphology, long rods in SBA-15-L and hexagonal dishes in SBA-15-S.

XRD patterns of commercial amorphous silica, MS-3030, and amino-functionalized sample, MS-3030-N, show disordered structure with no reflections at low diffraction angles (data not shown). These materials were used to compare the effect of the structure and pore diameter with OMMs. Figure 3 shows the SEM images of MS-3030 (Figure 3A) and MS-3030-N (Figure 3B) revealing fragmented spherical particles with diameter around $74 \mu \mathrm{m}$, indicating that there is no alteration in silica morphology after amine-functionalization with aminopropyltriethoxysilane (APTS). 
Figure 2. TEM images of calcined SBA-15-L in the direction perpendicular to the pore axis (A) and SBA-15-S in the direction of the pore axis (B).
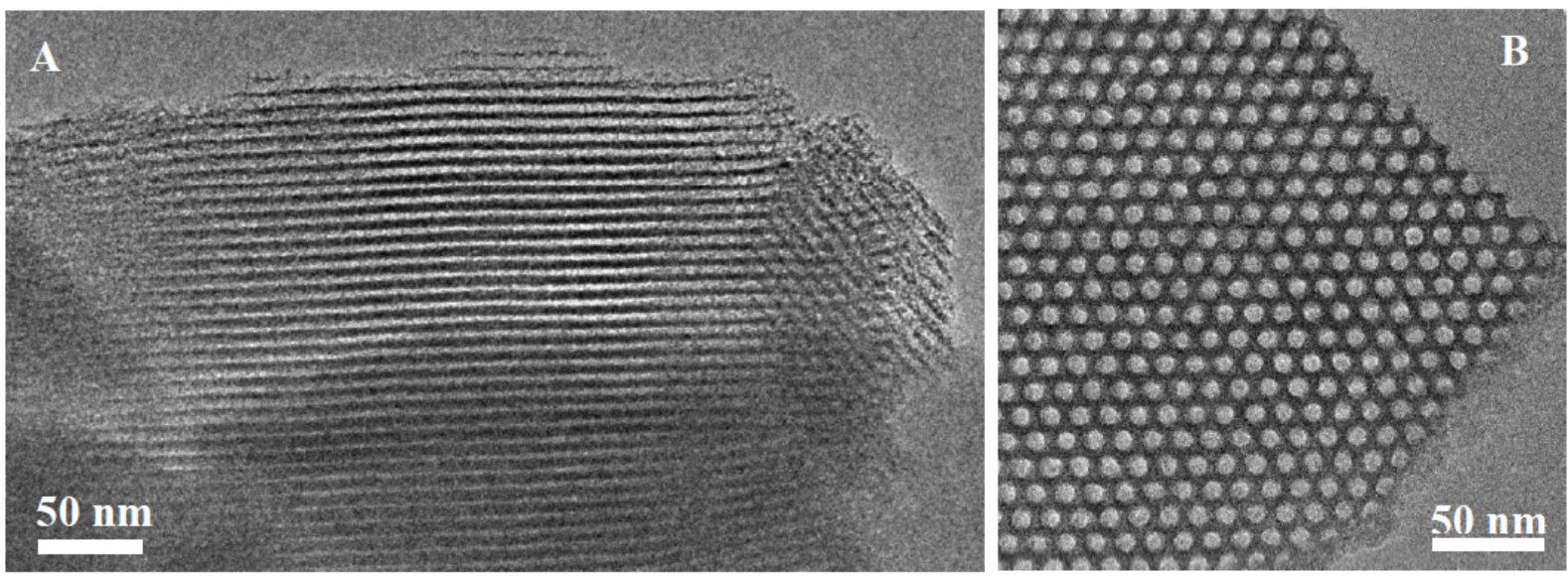

Figure 3. SEM micrographs of amorphous silicas: MS-3030 (A) and MS-3030-G-N (B).

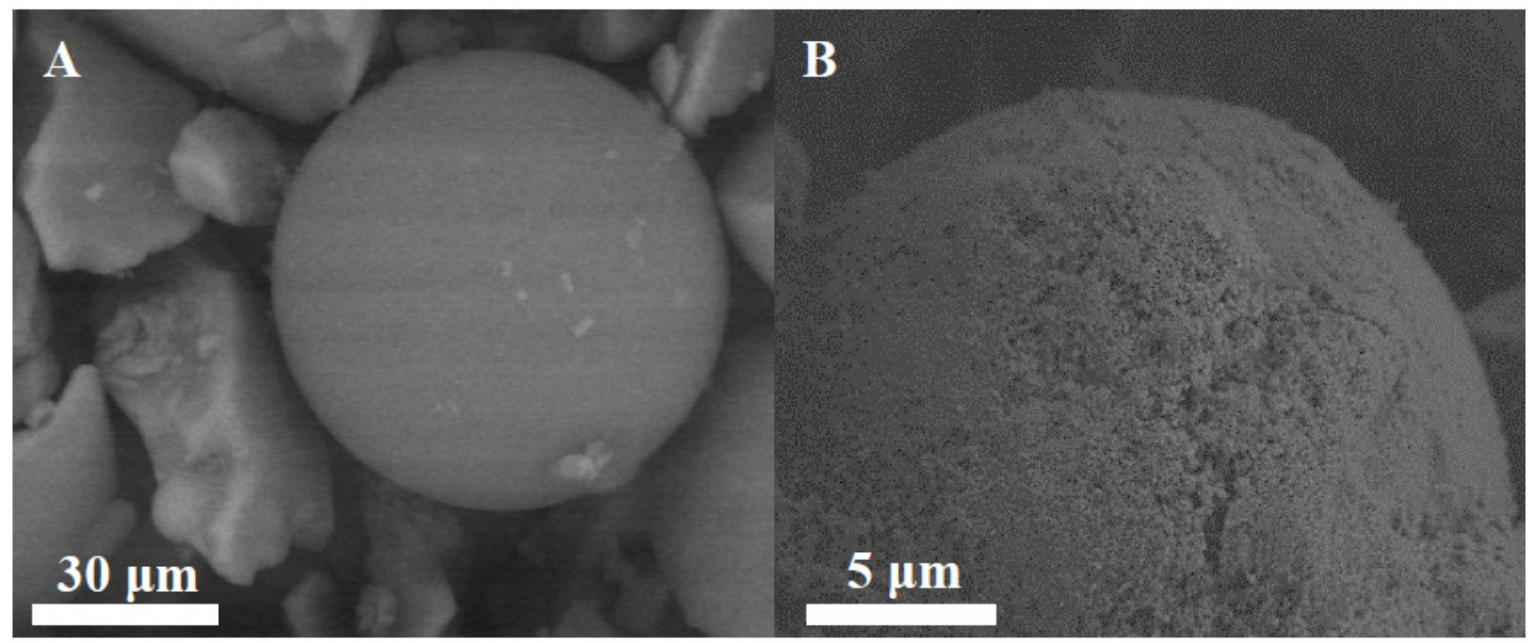

SBA-15-L and SBA-15-S exhibit type IV nitrogen adsorption-desorption isotherms with hysteresis loops of $\mathrm{H} 1$ type associated with capillarity condensation at high relative pressure $\left(\mathrm{P} / \mathrm{P}_{\mathrm{o}} 0.7-0.8\right)$, which is characteristic of mesoporous materials with hexagonal arrangement of cylindrical pore channels (Figure 4A). Pore size distribution curves calculated from the adsorption branch of the isotherms are shown in the inset of Figure 4A. The curves show very narrow pore size distribution with 7.8 and $6.4 \mathrm{~nm}$ mean pore size, respectively. SBA-15-L has a surface are of $609 \mathrm{~m}^{2} / \mathrm{g}$ and pore volume of $1.0 \mathrm{~cm}^{3} / \mathrm{g}$ and SBA-15-S has $550 \mathrm{~m}^{2} / \mathrm{g}$ and $0.7 \mathrm{~cm}^{3} / \mathrm{g}$, respectively.

The $\mathrm{N}_{2}$ isotherms of amorphous silica before and after functionalization (MS-3030 and MS-3030-N) are shown in Figure 4B. Both materials exhibited type IV isotherms, corresponding to mesoporous materials. The pore size distribution curves of amorphous materials show a wider range, indicating heterogeneity in the porous structure with average pore diameter of $30 \mathrm{~nm}$. As compared to MS-3030, MS-3030-N exhibited an expected slight decrease in BET surface area (from 296 to $236 \mathrm{~m}^{2} / \mathrm{g}$ ) and pore volume (from 2.5 to $2.1 \mathrm{~cm}^{3} / \mathrm{g}$ ) due to grafting of aminopropyl organic chains. The incorporation of the amine functional groups by grafting has been confirmed by elemental analysis yielding a $1.81 \mathrm{mmol} \mathrm{N}$ per gram of $\mathrm{SiO}_{2}$ in MS-3030-N material. 
Figure 4. $\mathrm{N}_{2}$ adsorption-desorption isotherms and pore size distributions: (A) SBA-15-L and SBA-15-S; (B) MS-3030 and MS-3030-N.

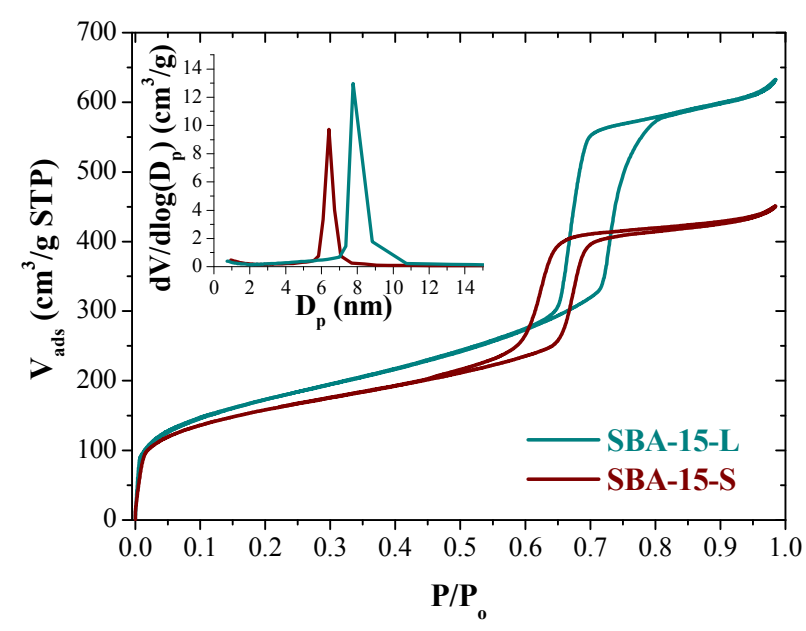

A

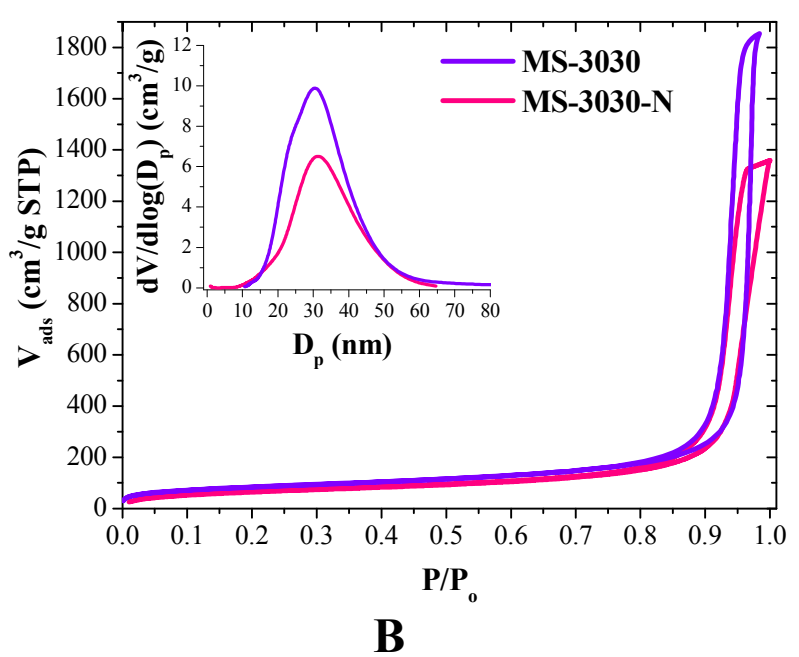

B

\subsection{Immobilization of Laccase and Specific Activity}

The laccase used in this work was manufactured by pure culture fermentation of a genetically modified strain of Aspergillus oryzae that contains the laccase gene derived from Myceliophthora thermophila. Bioinformatics analysis was used to determine the aminoacid sequence and 3D structure of this commercial laccase because the crystal structure is not solved yet and its dimensions have not been reported. An image of the laccase has been reconstructed and visualized using the software package PyMOL [27]. With the use of PyMOL and repeated rotations of the enzyme molecule, the average molecular size of laccase was found to be approximately $6.1 \mathrm{~nm} \times 5.0 \mathrm{~nm} \times 4.9 \mathrm{~nm}$ (Figure 5A).

Figure 5. (A) Average dimensions of laccase measured in PyMOL $(\sim 6.1 \mathrm{~nm} \times 5.0 \mathrm{~nm} \times$ $4.9 \mathrm{~nm}$ ). (B) Surface distribution of amino acids in laccase constructed in PyMOL (blue, basic amino acids; red, acidic amino acids; orange, polar amino acids; white, nonpolar amino acids; pink, copper atoms).
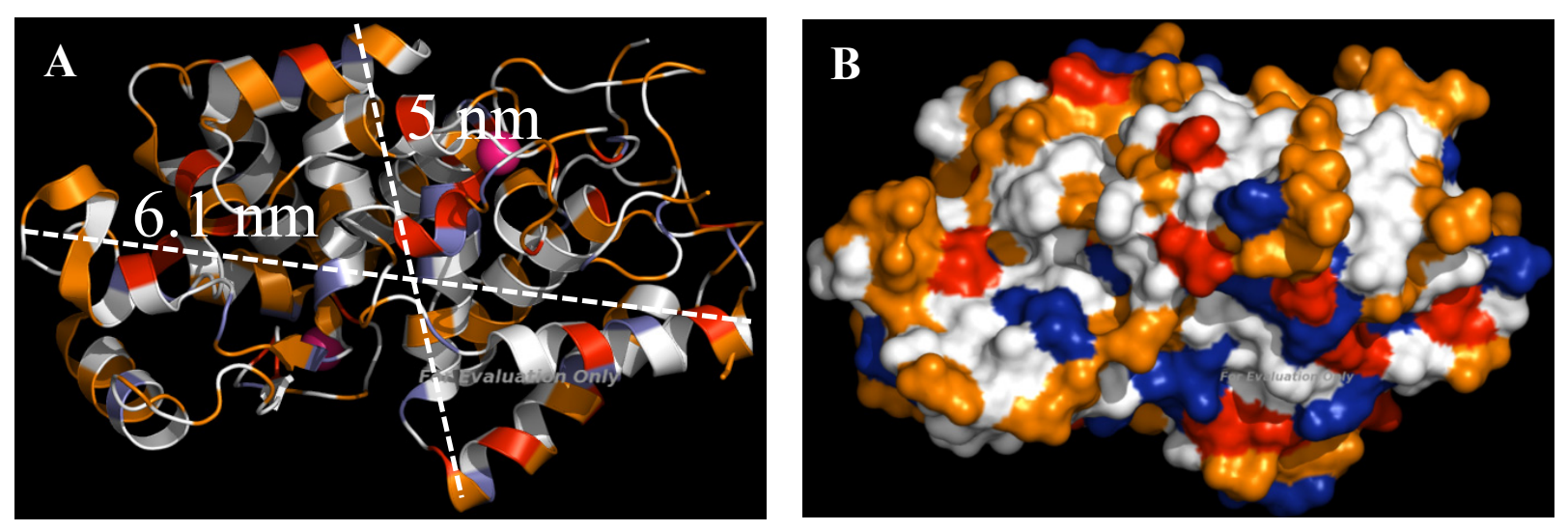

The molecular weight estimates for the laccase obtained from SDS-PAGE gel electrophoresis is around $80 \mathrm{kDa}$, consistent with other authors [28]. According to the enzyme dimensions and to the 
modelling studies and the textural properties of the supports, adsorption inside the pores of SBA-15 materials should be enabled. The surface distribution of amino acids in laccase is displayed in Figure 5B.

Electrostatic interactions between laccase molecules and the inner mesopore wall were considered for enzyme immobilization. Immobilization of laccase was achieved by suspending purely siliceous materials (SBA-15-L, SBA-15-S and MS-3030) in laccase solution at $\mathrm{pH}$ 3.5. In these conditions, laccase molecules bear a positive net charge (isoelectric point ( $\mathrm{pI}$ ) of laccase is 4.2). The silanol groups inside the mesopores are deprotonated at $\mathrm{pH} 3.5$ bearing a negatively charged surface, because their isoelectric point is about 2.0 .

Both ordered materials are similar in textural properties. However, despite the moderately lower surface area and pore diameter of SBA-15-S, this support exhibited moderately higher adsorption capacity compared to SBA-15-L (38.41 mg/g vs. $31.28 \mathrm{mg} / \mathrm{g})$. The main difference comes from the different support morphology highlighting the influence of this parameter on laccase immobilization. A schematic illustration is proposed (Figure 6) showing the immobilization of laccase on the two different supports. Laccase dimensions are of similar magnitude than channels pore size, so the presence of an enzyme molecule inside may prevent the access of another one, acting as a stopper or at least making enzyme diffusion more difficult. Therefore, despite the smaller pore diameter of SBA-15-S, its shorter channels (of about $170 \mathrm{~nm}$ ) can accommodate more enzyme molecules per unit length than the longer ones of SBA-15-L (1,000 nm length) where a part of the inner surface of the channel is not accessible to laccase molecules. This also explains why this material having a higher surface area does not result in a higher immobilization yield. This behavior has also been observed by other authors. According to Fan and coworkers [29], a SBA-15 sample with rod-like macromorphology displays faster loading kinetics and a higher loading capacity for lysozyme than an SBA-15 sample with fiber-like morphology. So, the morphology of OMM particles plays a significant role in the efficiency of enzyme immobilization.

Figure 6. Schematic illustration of the laccase immobilization on SBA-15-L mesochannels (A) and SBA-15-S mesochannels (B).

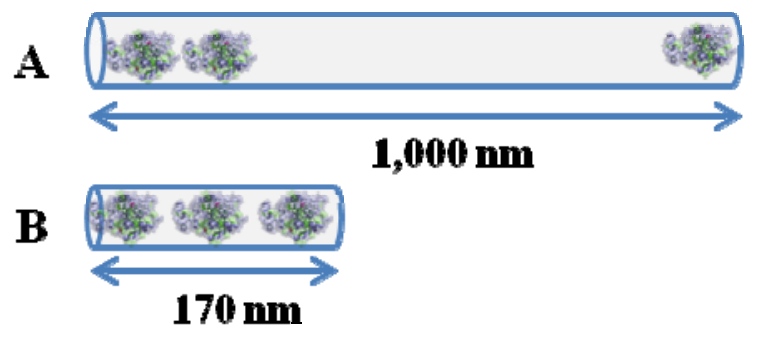

Regarding specific activity, the longer channels seem to challenge the diffusion of substrates and products more than the shorter ones, as suggested by the lower value in the long-channel SBA-15-L.

The isoelectric points of the support and the enzyme are close, so the charge densities at $\mathrm{pH} 3.5$ are low. Grafting the support with amine groups shifts its $\mathrm{pI}$ to higher value, so the interval becomes larger Protonated terminal amine groups can interact with deprotonated residues of aspartic acid and glutamic acid (pKa 4) at $\mathrm{pH} 5.5$ which is an intermediate value between isoelectric points of enzyme and amino-modified support, and it is far from these values. Therefore the respective densities of charge should be higher than in the systems enzyme-siliceous supports at $\mathrm{pH} 3.5$. These high charge densities 
should drive stronger electrostatic interactions and favor the immobilization of laccase. However, the close sizes of enzyme and pore diameter does not enable to functionalize SBA-15 materials while leaving enough room for enzyme diffusion, therefore a commercial siliceous material, MS-3030, with wider pores was used for comparison. The $30 \mathrm{~nm}$ average pore size of this amorphous material permits functionalization without compromising the access or diffusion of enzyme molecules. Figure 7 and Table 1 displays the adsorption of laccase on purely siliceous materials (SBA-15-L, SBA-15-S and MS-3030 at $\mathrm{pH} 3.5$ ) and amine grafted amorphous silica (MS-3030-N at $\mathrm{pH} 3.5$ and $\mathrm{pH} 5.5$ ) for initial amount of enzyme solution of $50 \mathrm{mg} / \mathrm{g}$ support.

Figure 7. Adsorption capacity of different supports. Solid bars: immobilization at $\mathrm{pH} 3.5$. Dashed bar: immobilization at $\mathrm{pH}$ 5.5.

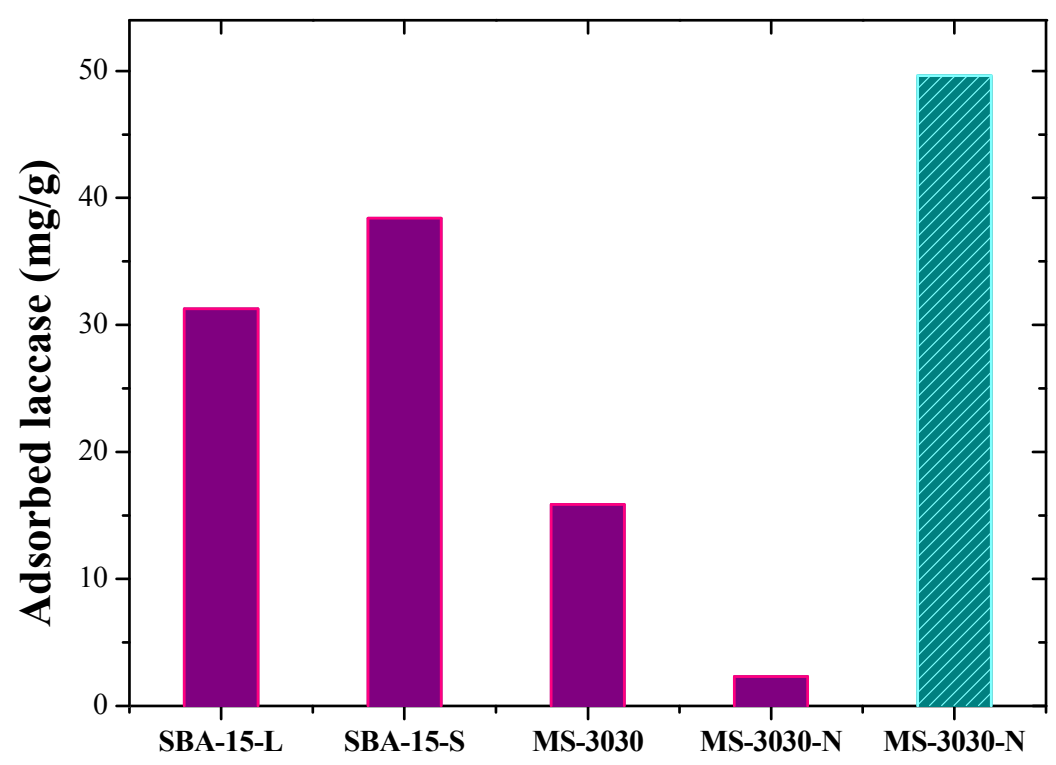

Table 1. Laccase immobilization characteristics and catalytic results for initial amount of enzyme solution of $50 \mathrm{mg} / \mathrm{g}$ support.

\begin{tabular}{cccccc}
\hline Support & pH immob. $^{\mathbf{a}}$ & $\boldsymbol{t}_{\boldsymbol{c}}(\mathbf{h})$ & \% $^{\mathbf{b}}$ Immob. $^{\mathbf{c}}$ & Enzyme loading (mg/g) $^{\mathbf{d}}$ & Specific activity (U/mg) $^{\mathbf{e}}$ \\
\hline SBA-15-L & 3.5 & 3 & 62.56 & 31.28 & 0.134 \\
SBA-15-S & 3.5 & 3 & 76.82 & 38.41 & 0.159 \\
MS-3030 & 3.5 & 3 & 31.76 & 15.88 & 0.014 \\
MS-3030-N & 5.5 & 3 & 99.28 & 49.64 & 0.981 \\
\hline
\end{tabular}

${ }^{\mathrm{a}} \mathrm{pH}$ of immobilization; ${ }^{\mathrm{b}}$ The time contact $\left(t_{c}\right)$ is the time required to reach a constant activity of the supernatant towards the oxidation of syringaldazine, indicative of maximum loading in the solid; ${ }^{\mathrm{c}}$ percent yield of immobilization; ${ }^{d}$ The enzyme loading is expressed in milligrams of enzyme per gram of material; e The specific activity is expressed in units of syringaldazine converted per milligram of enzyme inside the material. Specific activity of soluble laccase: $5.68 \mathrm{U} / \mathrm{mg}$.

Laccase was also adsorbed on purely siliceous MS-3030 at $\mathrm{pH} 3.5$ with poor results: $15.88 \mathrm{mg} / \mathrm{g}$ in the same immobilization time of $3 \mathrm{~h}$. The pore tortuosity and large particle size of this material may result in a slower diffusion of enzyme through the pore network despite the wider average pore size of $30 \mathrm{~nm}$. Immobilization on MS-3030-N at $\mathrm{pH} 3.5$ was negligible (2.32 mg/g, results not shown) because of electrostatic repulsion between the positively charged enzyme and the protonated amino 
groups of the support. However, immobilization on MS-3030-N performed at $\mathrm{pH} 5.5$ gave a $99 \%$ yield despite the surface area is only $296 \mathrm{~m}^{2} / \mathrm{g}$. At this $\mathrm{pH}$, enzyme and support surfaces have opposite charges and high charge densities, which favors strong electrostatic interactions. This phenomenon indicates that amino groups are appropriate for laccase immobilization at a suitable $\mathrm{pH}$.

The activity of the biocatalysts was tested in the oxidation of syringaldazine. Table 1 shows that the presence of the amine moieties in MS-3030-N also improves the specific activity of the laccase. SBA-15-L and SBA-15-S display higher activity than MS-3030, probably due to slower diffusion of substrate and product through the tortuous porous network and the larger particle size of this latter material. In contrast, SBA-15 materials offer an ordered structure with high pore connectivity and they are assembled with smaller particles than amorphous silica, which should favor a shorter diffusion course [30]. Other authors have also shown that materials with pore sizes much larger than the enzyme size have an adverse effect on enzyme activity [31].

\subsection{Leaching Test of Immobilized Laccase}

The extent of leaching of laccase from the inner structure of supports in aqueous media and the presence of laccase inside the porous network of the materials after the leaching tests have been studied due to the non-covalent nature of the enzyme-support binding through electrostatic interactions. Biocatalysts were incubated in aqueous solution of low ionic strength buffer and high dilution at $\mathrm{pH}$ 4.5. In these conditions, weak repulsion is established between negatively charged SBA-15-L or SBA-15-S and laccase, and weak attraction is still maintained between the positively charged MS-3030-N support and negatively charged laccase. In both cases low ionic strength buffered solution is used just to preserve $\mathrm{pH}$ without forcing enzyme leaching due to ionic competition anion-enzyme. These conditions are expected to favor enzyme desorption from the siliceous materials more than from the amino-modified one. Figure 8 summarizes these results, plotting the percentage of the initial enzyme loading leached with time.

Figure 8. Leaching of enzyme from materials, expressed as percent of the initial enzyme loading released as a function of time.

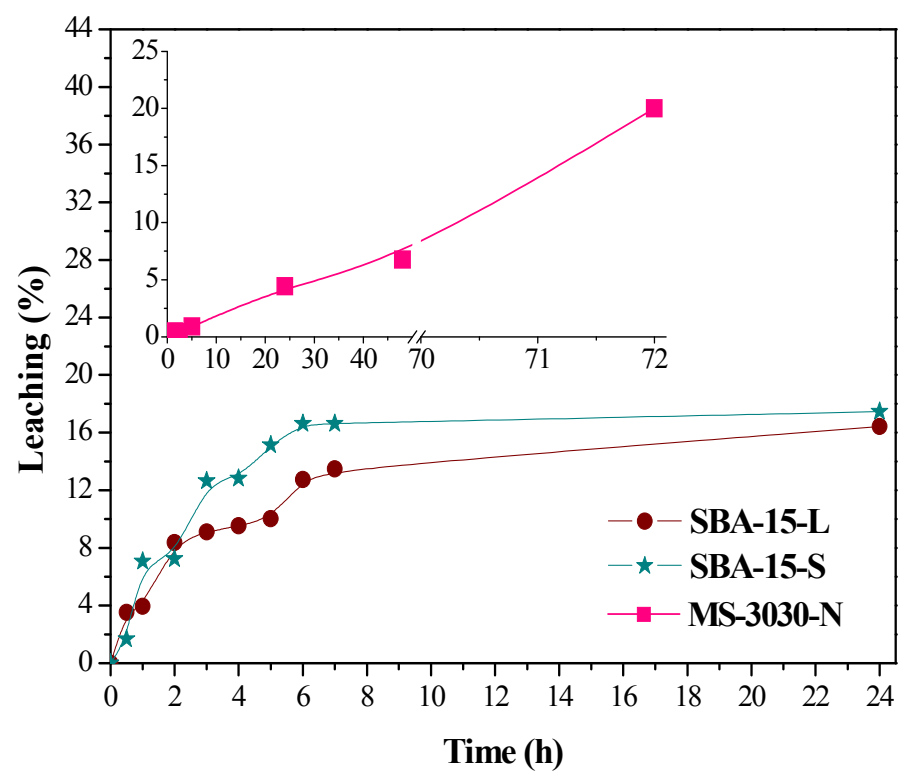


Two different kinds of patterns can be distinguished. Leaching profile in SBA-15-L and SBA-15-S showed fast initial desorption values and a plateau suggesting that the narrow pore size and confinement of the laccase minimize leaching of the enzyme from the inner surfaces. The first initial slope is probably due to enzyme molecules immobilized on external surfaces or close to the pore edges of the OMM particles.

Despite the electrostatic attraction between the enzyme molecules and functional groups on the surface remaining at $\mathrm{pH} 4.5$, amine amorphous silica (MS-3030-N) shows a continuous and fast release of enzyme, without reaching an equilibrium point in the range of time studied (up to $72 \mathrm{~h}$ ). This material with much larger pore diameter offers no restriction to enzyme diffusion and is highly susceptible to leaching during the operation. The confinement of the enzyme inside pores seems to be more efficient to prevent leaching than the intensity of interaction with support.

From leaching tests, some laccase molecules seem to be adsorbed on the external surface of SBA-15 particles. In order to check the presence of enzyme inside particles, the biocatalysts previously incubated under the leaching conditions described above were treated in denaturing conditions of SDS-PAGE and their supernatants were assayed for electrophoresis. Linear polypeptide chain should easily exit the pores after this treatment and be detected in the supernatants. Bands were observed for all the samples which confirm that the enzyme is adsorbed inside the pores of amorphous silica and both SBA-15 materials (Figure 9). Leaching profile of MS-3030 is not displayed because laccase molecules were released from the support during biocatalyst washing due to wide pores and weak attraction; moreover the protein band obtained by electrophoresis is very thin (Figure 9, lane 5).

Figure 9. Electrophoresis in standard conditions. 1: Protein standard (high range SDS-Page standard stained with coomassie G-250 stain; 2: Soluble laccase; 3: SBA-15-L; 4: SBA-15-S; 5: MS-3030; 6: MS-3030-N.

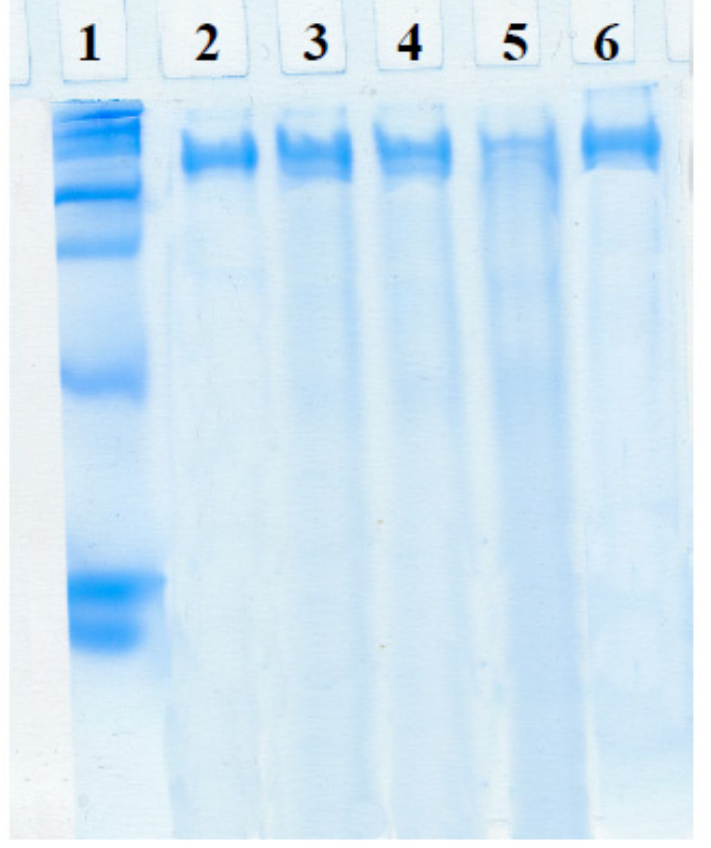




\section{Experimental}

\subsection{Synthesis of the Supports}

Synthesis of SBA-15-L. Pure silica SBA-15 with elongated rod particles was synthesized by using Pluronic P123 triblock copolymer according to the bibliography [32]. First, Pluronic P123 (4 g) was dissolved at room temperature in $1.9 \mathrm{M}$ aqueous $\mathrm{HCl}$ solution $(125 \mathrm{~mL})$. The resulting solution was slowly stirred at $25{ }^{\circ} \mathrm{C}$ until the solution became clear. TEOS $(9.25 \mathrm{~mL})$ was then added to the solution and the resulting mixture was vigorously stirred at $40{ }^{\circ} \mathrm{C}$ for $20 \mathrm{~h}$. Aging was then performed at $110{ }^{\circ} \mathrm{C}$ under static conditions for $24 \mathrm{~h}$ in a closed Teflon container. Finally, the white solid product was recovered by filtration, washed with water, air dried at room temperature and calcined at $550{ }^{\circ} \mathrm{C}$ in air for $5 \mathrm{~h}$ in a furnace for removal of the surfactant.

Synthesis of SBA-15-S. Pure silica SBA-15 with dish-shaped particles was synthesized using Pluronic PE-10400 as structure directing agent and with tetramethylorthosilicate (TMOS) as the silica source. This material has prepared according to the method reported by Linton et al. [33,34]. PE-10400 $(2.5 \mathrm{~g})$ was dissolved in $1.6 \mathrm{M}$ aqueous $\mathrm{HCl}$ solution $(97.5 \mathrm{~g})$. The mixture was stirred at room temperature in a closed Teflon container until a homogeneous clear solution was obtained. Then, the solution was heated at $55^{\circ} \mathrm{C}$ for $1 \mathrm{~h}$, after which TMOS $(3.8 \mathrm{~g})$ was added and stirred vigorously at $55^{\circ} \mathrm{C}$ for $24 \mathrm{~h}$. Subsequently, the container was transferred to an oven and kept at $80{ }^{\circ} \mathrm{C}$ for $24 \mathrm{~h}$ under static conditions. The resultant product was filtered, washed thoroughly with dry ethanol and air-dried at room temperature overnight. Finally, the surfactant template was removed by calcination at $550{ }^{\circ} \mathrm{C}$ for $5 \mathrm{~h}$ in air.

Functionalization of MS-3030 by grafting with aminopropyl groups (MS-3030-N). Commercial mesoporous amorphous silica material, MS-3030 manufactured by PQ Corporation (Conshohocken, PA, USA), was functionalized with aminopropyl groups by silanization reaction of surface silanol groups with aminopropyltriethoxysilane (APTES) $[8,35]$. Silica powder $(5 \mathrm{~g})$ was placed in a round bottom flask and degassed at $80{ }^{\circ} \mathrm{C}$ under vacuum for $20 \mathrm{~h}$ to remove adsorbed water [7]. This dried material was dispersed in dry toluene $(100 \mathrm{~mL})$, and APTES $(25 \mathrm{~g})$ was added under constant stirring. The reaction mixture was refluxed under stirring at atmospheric pressure in a nitrogen atmosphere for $24 \mathrm{~h}$. After a slow cooling of the reaction mixture, the resulting amino-functionalized material was recovered by filtration, washed twice with dry toluene for removal of unreacted reagent, followed by three times with acetone, and finally dried under vacuum for $24 \mathrm{~h}$.

\subsection{Characterization Techniques}

X-ray diffraction (XRD) patterns were acquired with a X'PERT diffractometer (PANalytical, Almelo, The Netherlands) using the $\mathrm{Cu}-\mathrm{K}_{\alpha}(\lambda=1.5406 \AA)$ radiation. The data were registered with two theta step size $0.02^{\circ}$ and accumulation time $20 \mathrm{~s}$. Transmission electron micrographs (TEM) were obtained on a JEM-2100 electron microscope (JEOL, Akishima, Japan) operated at $200 \mathrm{kV}$. A small amount of sample powder was dispersed in ethanol and dropped on a holey carbon coated copper grid. Scanning electron microscopy (SEM) images were collected with a Nova NanoSEM 230 FE-SEM microscope (FEI, Eindhoven, The Netherlands) with vCD detector. The samples were prepared by placing material powder on double-sided graphite adhesive tape mounted on the sample holder. 
Nitrogen adsorption-desorption isotherms were measured at $-196{ }^{\circ} \mathrm{C}$ on an ASAP 2420 device (Micromeritics, Norcross, GA, USA). All calcined silicas before enzyme immobilization were outgassed at $350{ }^{\circ} \mathrm{C}$ for $16 \mathrm{~h}$ under high vacuum prior to the measurements. The specific surface area, $S_{B E T}$, was calculated from nitrogen adsorption data in the relative pressure range from 0.04 to 0.2 using the BET (Brunauer-Emmett-Teller) method. The total pore volume, $V_{p}$, was determined from the amount of nitrogen adsorbed at a relative pressure of 0.97 . Pore size distributions were determined from the adsorption branch of the $\mathrm{N}_{2}$ isotherms using the BJH (Barrett-Joyner-Halenda) model with cylindrical geometry of the pores. The $\mathrm{BJH}$ pore diameter, $\mathrm{D}_{\mathrm{p}} \mathrm{BJH}$, is defined as the position of the maximum of the pore size distribution. Quantitative determination of the nitrogen content of organofunctionalized support was performed using a CHNS-932 Elemental Analyser (LECO Corporation, St. Joseph, MI, USA) with an AD-4 autobalance (Perkin Elmer, Shelton, CT, USA). Thermogravimetric analyses were carried out using a TGA 7 instrument (Perkin Elmer). Samples were heated in air atmosphere from 25 to $900{ }^{\circ} \mathrm{C}$ at a rate of $20^{\circ} \mathrm{C} / \mathrm{min}$.

\subsection{Protein Determination and Activity Assay}

Protein content of commercial laccase extract was determined with the Bio-Rad Protein Assay (Bio-Rad, München, Germany), based on the Bradford assay [36], using bovine serum albumin (BSA) as protein standard. This extract was found to contain a protein concentration of $1.3 \mathrm{mg} / \mathrm{mL}$. Electrophoresis (lane 2 in Figure 9) showed a unique band, so all protein was assigned to laccase.

Enzymatic activity of free and immobilized laccase was determined spectrophotometrically by measuring the increase in absorbance at $530 \mathrm{~nm}$ caused by the oxidation of syringaldazine in the presence of atmospheric oxygen to tetramethoxyazobis(methylene) quinone [37,38], using an 8453 UV-Vis spectrophotometer (Agilent Technologies, Waldbronn, Germany) equipped with a stirring device and temperature control. The reaction mixture consisted of $2200 \mu \mathrm{L}$ of potassium dihydrogen phosphate/disodium hydrogen phosphate buffer ( $\mathrm{pH} 6.5,100 \mathrm{mM}), 60 \mu \mathrm{L}$ of $1 \mathrm{mM}$ syringaldazine solution dissolved in ethanol. $100 \mu \mathrm{L}$ of enzyme solution, suspension or supernatant, were added to the cuvette containing the above substrate solution under stirring and the reaction was monitored continuously for $5 \mathrm{~min}$ by measuring the absorption at $530 \mathrm{~nm}$ at $30{ }^{\circ} \mathrm{C}$. One laccase activity unit (U) is defined as the amount of enzyme required to oxidize $1 \mu \mathrm{mol}$ of syringaldazine per minute at $30{ }^{\circ} \mathrm{C}$ $\left(\varepsilon_{530} \mathrm{~nm}=65,000 \mathrm{M}^{-1} \mathrm{~cm}^{-1}\right)$. Each sample was measured three times, and the average value was used.

\subsection{Immobilization of Laccase on Mesoporous Silicates}

Immobilization of laccase on purely siliceous supports, namely SBA-15-L, SBA-15-S and MS-3030, was performed by suspending the materials in enzyme solutions at $\mathrm{pH} 3.5$ (50 mM citric acid/trisodium citrate buffer). Amino-functionalized material, MS-3030-N, was suspended in laccase solutions in $50 \mathrm{mM}$ acetic acid/sodium acetate buffer at $\mathrm{pH} 5.5$.

To $10 \mathrm{~mL}$ enzyme solutions (containing $2.5 \mathrm{mg}$ laccase), the support (50 mg) was added and left in suspension under slow rotation at room temperature to allow immobilization to occur by adsorption. Aliquots were withdrawn at given times, and the enzymatic activity of the suspension and supernatant were analyzed by the syringaldazine oxidation assay. The decrease in activity of the supernatant to a minimum and constant value indicated the end point of the immobilization process. At this equilibrium 
point, the solid was filtered off and washed with $50 \mathrm{mM}$ buffer (at the same $\mathrm{pH}$ as used for immobilization, $\mathrm{pH} 3.5$ or 5.5). The solid samples were first dried under vacuum and afterwards under dry nitrogen stream, and then stored at $4{ }^{\circ} \mathrm{C}$ in the refrigerator for later analysis. A mass balance was applied to calculate the amount of enzyme immobilized on the supports.

To evaluate the enzymatic activity of laccase immobilized on mesoporous silicas, $10 \mathrm{mg}$ of the respective dried biocatalysts were resuspended in $1 \mathrm{~mL}$ of $50 \mathrm{mM}$ buffer $(\mathrm{pH} 3.5$ for biocatalysts prepared with purely siliceous supports or $\mathrm{pH} 5.5$ for those on amino-silica supports) and analyzed for remaining laccase activity by the syringaldazine oxidation assay.

\subsection{Immobilized Laccase Leaching Tests}

To measure the leaching of laccase from the supports, samples of the solid containing the enzyme were suspended in $50 \mathrm{mM}$ acetic acid/sodium acetate at $\mathrm{pH} 4.5$ and the solid/liquid ratio was $1.25 \mathrm{mg} / \mathrm{mL}$. At different times aliquots of the suspensions were withdrawn and centrifuged, and the protein content of the supernatants was measured according to Bradford assay [36].

\subsection{SDS-PAGE Electrophoresis}

An attempt to verify the location of laccase inside the porous network of the materials was made. Since solid samples are not suitable for electrophoresis, the enzyme was forced to exit the pores. First, the laccase immobilized on different materials was suspended in buffered solutions for $24 \mathrm{~h}$ at $\mathrm{pH} 4.5$ as described above to desorb all protein molecules adsorbed on the external surface of support particles. The filtered solids were suspended in electrophoresis sample buffer (containing sodium dodecyl sulfate, mercaptoethanol, bromophenol blue, Tris/HCl buffer $\mathrm{pH} 6.8$ and glycerol) in the same amounts as in electrophoresis samples, and boiled for $5 \mathrm{~min}$. In such denaturing conditions, the tertiary structure of the protein should be lost and the lineal peptide chain should then be easily released from the pores. The supernatants of these suspensions after centrifuging were withdrawn and analyzed by SDS-PAGE electrophoresis [39].

\section{Conclusions}

Two similar ordered mesoporous materials with well-defined morphologies and highly uniform particle sizes synthesized using surfactant templates in acidic solutions were tested as supports for laccase immobilization. The morphology of SBA-15 demonstrated to play a significant role in the efficiency of enzyme immobilization. Short SBA-15-S channels proved to be more efficient to carry higher enzyme loading whereas restriction to enzyme diffusion in the longer SBA-15-L channels resulted in lower enzyme loading and higher retention (or less leaching). Also, some restriction to the diffusion of substrate or product may drive a lower specific activity.

The relevance of the pore and particle features was also demonstrated by the comparison with an amorphous meso-macroporous siliceous material, where electrostatic interactions were strengthen by the presence of amine groups. Despite immobilization yield was higher in this material, leaching of the enzyme had no restriction. However, the confinement in SBA-15 channels was more efficient to retain enzyme. 
Our results on the immobilization of laccase on ordered mesoporous materials (SBA-15-L and SBA-15-S) demonstrate the importance of matching pore diameter and enzyme dimensions and chemical affinity (MS-3030-N). Efficient immobilization of laccase can be improved when a detailed understanding of the enzyme properties is combined with a tailored design of mesoporous supports. The aim should be now to synthesize ordered mesoporous materials with larger pore diameter and to incorporate amine groups.

\section{Acknowledgments}

The authors thank the Spanish Government for financial support through the project MAT 2012-31127, and Ramiro Martinez (Novozymes, Spain) for his kind help with the supply of laccase. V. G. acknowledges Ministerio de Educación, Cultura y Deporte for a FPU PhD fellowship.

\section{Author Contributions}

V. Gascón performed the experimental work and wrote the paper. Supervision of the work with ordered siliceous materials by C. Marquez and I Diaz. Supervision of the work with enzymes by R M Blanco. Supervision of the manuscript writing by Marquez, Diaz and Blanco.

\section{Conflicts of Interest}

The authors declare no conflict of interest.

\section{References}

1. Hartmann, M. Ordered mesoporous materials for bioadsorption and biocatalysis. Chem. Mater. 2005, 17, 4577-4593.

2. Hudson, S.; Magner, E.; Cooney, J.; Hodnett, B.K. Methodology for the immobilization of enzymes onto mesoporous materials. J. Phys. Chem. B 2005, 109, 19496-19506.

3. Serra, E.; Mayoral, A.; Sakamoto, Y.; Blanco, R.M.; Diaz, I. Immobilization of lipase in ordered mesoporous materials: Effect of textural and structural parameters. Microporous Mesoporous Mater. 2008, 114, 201-213.

4. Hartmann, M.; Kostrov, X. Immobilization of enzymes on porous silicas-Benefits and challenges. Chem. Soc. Rev. 2013, 42, 6277-6289.

5. Zhou, Z.; Hartmann, M. Progress in enzyme immobilization in ordered mesoporous materials and related applications. Chem. Soc. Rev. 2013, 42, 3894-3912.

6. Chong, A.S.M.; Zhao, X.S. Functionalization of SBA-15 with APTES and characterization of functionalized materials. J. Phys. Chem. B 2003, 107, 12650-12657.

7. Blanco, R.M.; Terreros, P.; Fernandez-Perez, M.; Otero, C.; Diaz-Gonzalez, G. Functionalization of mesoporous silica for lipase immobilization - Characterization of the support and the catalysts. J. Mol. Catal. B: Enzym. 2004, 30, 83-93.

8. Vinu, A.; Hossain, K.Z.; Ariga, K. Recent advances in functionalization of mesoporous silica. J. Nanosci. Nanotechnol. 2005, 5, 347-371. 
9. Aguado, J.; Arsuaga, J.M.; Arencibia, A.; Lindo, M.; Gascon, V. Aqueous heavy metals removal by adsorption on amine-functionalized mesoporous silica. J. Hazard. Mater. 2009, 163, 213-221.

10. Athens, G.L.; Shayib, R.M.; Chmelka, B.F. Functionalization of mesostructured inorganic-organic and porous inorganic materials. Curr. Opin. Colloid Interface Sci. 2009, 14, 281-292.

11. Zhao, X.S.; Bao, X.Y.; Guo, W.; Lee, F.Y. Immobilizing catalysts on porous materials. Mater. Today 2006, 9, 32-39.

12. Tran, D.N.; Balkus, K.J. Perspective of recent progress in immobilization of enzymes. ACS Catal. 2011, 1, 956-968.

13. Zhou, Y.; Wan, M.M.; Gao, L.; Lin, N.; Lin, W.G.; Zhu, J.H. One-pot synthesis of a hierarchical PMO monolith with superior performance in enzyme immobilization. J. Mater. Chem. B 2013, 1, $1738-1748$.

14. Leonowicz, A.; Cho, N.S.; Luterek, J.; Wilkolazka, A.; Wojtas-Wasilewska, M.; Matuszewska, A.; Hofrichter, M.; Wesenberg, D.; Rogalski, J. Fungal laccase: Properties and activity on lignin. J. Basic Microbiol. 2001, 41, 185-227.

15. Mayer, A.M.; Staples, R.C. Laccase: New functions for an old enzyme. Phytochem. Rev. 2002, $60,551-565$.

16. Baldrian, P. Fungal laccases-Occurrence and properties. FEMS Microbiol. Rev. 2006, 30, 215-242.

17. Kunamneni, A.; Plou, F.J.; Ballesteros, A.; Alcalde, M. Laccases and their applications: A patent review. Recent Pat. Biotechnol. 2008, 2, 10-24.

18. Brijwani, K.; Rigdon, A.; Vadlani, P.V. Fungal laccases: Production, function, and applications in food processing. Enzym. Res. 2010, 2010, 149748.

19. Minussi, R.C.; Pastore, G.M.; Duran, N. Potential applications of laccase in the food industry. Trends Food Sci. Technol. 2002, 13, 205-216.

20. Rodriguez Couto, S.; Toca Herrera, J.L. Industrial and biotechnological applications of laccases: A review. Biotechnol. Adv. 2006, 24, 500-513.

21. Riva, S. Laccases: Blue enzymes for green chemistry. Trends Biotechnol. 2006, 24, $219-226$.

22. Morozova, O.V.; Shumakovich, G.P.; Shleev, S.V.; Yaropolov, Y.I. Laccase-mediator systems and their applications: A review. Appl. Biochem. Microbiol. 2007, 43, 523-535.

23. Li, Y.; Jiang, G.; Niu, J.; Wang, Y.; Hu, L. Laccase-catalyzed oxidation of organic pollutants in water. Prog. Chem. 2009, 21, 2028-2036.

24. Osma, J.F.; Toca-Herrera, J.L.; Rodriguez-Couto, S. Uses of laccases in the food industry. Enzym. Res. 2010, 2010, 918761.

25. Kudanga, T.; Nyanhongo, G.S.; Guebitz, G.M.; Burton, S. Potential applications of laccase-mediated coupling and grafting reactions: A review. Enzym. Microb. Technol. 2011, 48, 195-208.

26. Fernandez-Fernandez, M.; Sanroman, M.A.; Moldes, D. Recent developments and applications of immobilized laccase. Biotechnol. Adv. 2013, 31, 1808-1825.

27. DeLano, W.L. The PyMOL Molecular Graphics System. Available online: http://www.pymol.org/ (accessed on 14 January 2014).

28. Berka, R.M.; Schneider, P.; Golightly, E.J.; Brown, S.H.; Madden, M.; Brown, K.M.; Halkier, T.; Mondorf, K.; Xu, F. Characterization of the gene encoding an extracellular laccase of Myceliophthora 
thermophila and analysis of the recombinant enzyme expressed in Aspergillus oryzae. Appl. Environ. Microbiol. 1997, 63, 3151-3157.

29. Fan, J.; Lei, J.; Wang, L.M.; Yu, C.Z.; Tu, B.; Zhao, D.Y. Rapid and high-capacity immobilization of enzymes based on mesoporous silicas with controlled morphologies. Chem. Commun. 2003, 2140-2141.

30. Fernandez, O.; Diaz, I.; Torres, C.F.; Tobajas, M.; Tejedor, V.; Blanco, R.M. Hybrid composites octyl-silica-methacrylate agglomerates as enzyme supports. Appl. Catal. A 2013, 450, 204-210.

31. Weber, E.; Sirim, D.; Schreiber, T.; Thomas, B.; Pleiss, J.; Hunger, M.; Glaser, R.; Urlacher, V.B. Immobilization of P450 BM-3 monooxygenase on mesoporous molecular sieves with different pore diameters. J. Mol. Catal. B-Enzym. 2010, 64, 29-37.

32. Zhao, D.Y.; Feng, J.L.; Huo, Q.S.; Melosh, N.; Fredrickson, G.H.; Chmelka, B.F.; Stucky, G.D. Triblock copolymer syntheses of mesoporous silica with periodic 50 to 300 angstrom pores. Science 1998, 279, 548-552.

33. Linton, P.; Alfredsson, V. Growth and Morphology of Mesoporous SBA-15 Particles. Chem. Mater. 2008, 20, 2878-2880.

34. Linton, P.; Rennie, A.R.; Zackrisson, M.; Alfredsson, V. In situ observation of the genesis of mesoporous silica SBA-15: Dynamics on length scales from $1 \mathrm{~nm}$ to 1 microm. Langmuir 2009, $25,4685-4691$.

35. Stein, A.; Melde, B.J.; Schroden, R.C. Hybrid inorganic-organic mesoporous silicates-Nanoscopic reactors coming of age. Adv. Mater. 2000, 12, 1403-1419.

36. Bradford, M.M. A rapid and sensitive method for the quantitation of microgram quantities of protein utilizing the principle of protein-dye binding. Anal. Biochem. 1976, 72, 248-254.

37. Leonowicz, A.; Grzywnowicz, K. Quantitative estimation of laccase forms in some white-rot fungi using syringaldazine as a substrate. Enzym. Microb. Technol. 1981, 3, 55-58.

38. Sanchez-Amat, A.; Solano, F. A pluripotent polyphenol oxidase from the melanogenic marine Alteromonas sp shares catalytic capabilities of tyrosinases and laccases. Biochem. Biophys. Res. Commun. 1997, 240, 787-792.

39. Laemmli, U.K. Cleavage of structural proteins during the assembly of the head of bacteriophage T4. Nature 1970, 227, 680-685.

Sample Availability: Not available.

(C) 2014 by the authors; licensee MDPI, Basel, Switzerland. This article is an open access article distributed under the terms and conditions of the Creative Commons Attribution license (http://creativecommons.org/licenses/by/3.0/). 